\title{
Carotid Artery Angioplasty and Stenting for Patients Less than 70 Years-of-Age
}

\author{
Ryan Alkins, Charles C. Matouk, Juan P. Cruz, Thomas Marotta, \\ Walter Montanera, Julian Spears
}

\begin{abstract}
Background: Recent studies have suggested that carotid artery angioplasty and stenting (CAS) is a safe alternative to carotid endarterectomy (CEA) in average risk patients $<70$ years of age. We examined a consecutive series of patients who underwent CAS in order to determine the influence of patient age on outcome. Methods: A retrospective, longitudinal cohort study of consecutive patients who underwent CAS at St. Michael's Hospital, Canada between January 2001 and November 2010 was performed. The outcome measures were 30-day stroke and 30-day composite death, stroke and acute myocardial infarction (MI). Patients were stratified based on age $<70$ and $\geq 70$ years. Results: One hundred and fifty-nine patients underwent 165 CAS procedures. The 30-day risk of stroke was $3.8 \%$ while the composite outcome of death/stroke/MI was $8.2 \%$. When stratified by age $<70$ and $\geq 70$ years, the $30-$ day stroke rate was $0 \%$ versus $7.4 \%(\mathrm{p}=0.03)$, and the composite outcome of death/stroke/MI was $2.6 \%$ versus $13.6 \%$ ( $\mathrm{p}=0.02)$, respectively. Conclusions: Patients $<70$ years of age undergoing CAS have a low rate of major complications, comparing favourably with historical CEA adverse event rates, and supporting the recent carotid stenosis literature that in the younger population CAS has a similar complication rate compared to CEA.
\end{abstract}

RÉSUMÉ: Angioplastie carotidienne et mise en place d'un stent chez les patients de moins de 70 ans. Contexte : Selon des études récentes, l'angioplastie carotidienne avec mise en place d'un stent (ACS) est une alternative sûre à l'endartérectomie carotidienne (EAC) chez les patients à risque moyen qui sont âgés de moins de 70 ans. Nous avons analysé des données d'une série consécutive de patients qui ont subi une ACS afin de déterminer quelle est l'influence de l'âge du patient sur le résultat. Méthode : Nous avons effectué une étude longitudinale rétrospective de cohorte de patients consécutifs qui ont subi une ACS au St.Michael's Hospital de Toronto au Canada, entre janvier 2001 et novembre 2010. Les critères d'évaluation étaient d'une part l'accident vasculaire cérébral (AVC) au cours des 30 jours suivant l'intervention et d'autre part un agrégat incluant le décès, l'accident vasculaire cérébral et l'infarctus du myocarde (IM) au cours des 30 jours suivant l'intervention. Les patients étaient répartis en deux groupes, selon qu'il avaient moins de 70 ans ou 70 ans et plus. Résultats : Cent cinquante-neuf patients ont subi 165 ACS. Le risque d'AVC dans les 30 jours suivant l'intervention était de 3,8\% et le risque de décès/AVC/IM était de 8,2\%. Après stratification pour l'âge, le taux d'AVC était de $0 \%$ versus 7,4\% ( $\mathrm{p}=0,03$ ) et le taux de décès/AVC/IM était de 2,6\% versus $13,6 \%(\mathrm{p}=0,02)$ respectivement. Conclusions : Les patients de moins de 70 ans qui subissent une ACS ont un taux de complications majeures qui est bas et qui se compare favorablement avec les taux historiques d'effets indésirables de l'EAC. Ces constatations appuient la littérature récente sur le traitement de la sténose carotidienne indiquant que l'ACS a un taux de complications similaire à celui de l'EAC chez les patients qui sont plus jeunes.

Can J Neurol Sci. 2012; 39: 338-342

Stroke is a leading cause of death and disability in North America. ${ }^{1,2}$ Much of the stroke burden is attributable to ischemic stroke, a significant proportion of which is related to carotid artery atherosclerosis. ${ }^{3}$ Treatment options typically include riskfactor modification, anti-platelet agents, and carotid revascularization. The benefits of carotid endarterectomy (CEA) over and above those of medical management, particularly in the secondary prevention of stroke, have been well studied. ${ }^{4-8}$ Carotid artery angioplasty and stenting (CAS) has emerged as an alternative to carotid endarterectomy, yet controversy remains regarding its precise role. The Stenting and AngioPlasty with Protection for Patients at HIgh Risk for Endarterectomy (SAPPHIRE) trial was the first to show a role for CAS in North American Symptomatic Carotid Endarterectomy Trial (NASCET)-ineligible patients, and CAS subsequently adopted this niche in the management of the high-surgical risk population. ${ }^{9}$ A number of studies comparing CAS and CEA in average surgical risk patients were unable to demonstrate noninferiority of CAS to CEA; ${ }^{10-12}$ however, recent studies have suggested an expanded role for CAS.
The Carotid Revascularization Endarterectomy versus Stenting Trial (CREST), the largest trial to date comparing CAS and CEA in the management of carotid stenosis and having enrolled over twenty-five hundred patients, was designed to address whether CAS represented an alternative to CEA for average-risk surgical patients. ${ }^{13}$ No statistically significant difference was found between CAS and CEA in the composite end-point of death, myocardial infarction (MI) and stroke. Previous studies have found a higher risk of stroke associated with $\mathrm{CAS}^{10-12}$, and CREST was no different; the equivalent

\footnotetext{
From the Division of Neurosurgery, Department of Surgery (RA, CCM, JS);

Neurovascular Program, Department of Medical Imaging (CCM, JPC, TM, WM, JS), St. Michael's Hospital, University of Toronto, Toronto, Ontario, Canada.

Received September 2, 2011. Final Revisions Submitted November 24, 2011 Correspondence to: Ryan Alkins, Division of Neurosurgery, St Michael's Hospital, 30 Bond Street, Toronto, Ontario, M5B 1W8, Canada. Email: ryan.alkins@utoronto.ca
} 
overall findings were the result of a combined endpoint with a higher risk of MI in patients treated with CEA. However, a subgroup analysis raised the possibility that, taking all primary endpoints into account, CAS may be safer than CEA for patients $<70$ years of age. ${ }^{13}$ Furthermore, although the International Carotid Stenting Study (ICSS) found a higher complication rate for CAS, ${ }^{14}$ a meta-analysis by the Carotid Stenting Trialists' Collaboration of the pooled results from the ICSS, EVA-3S, and SPACE reported comparable 120-day outcomes between CEA and CAS in patients' $\leq 70$ years of age. ${ }^{15}$ The purpose of this study was to determine the effect of age on complications of CAS in a cohort of patients managed at a single institution.

\section{METHODS}

Institutional research ethics board approval was obtained for a retrospective chart review of patients who underwent CAS at St. Michael's Hospital, Toronto, Canada between January 2001 and November 2010. Two patients stented for carotid dissection, both with previous CEA, were excluded. A small proportion of the patients undergoing CAS were also enrolled in CREST. The degree of carotid stenosis was measured on catheter angiograms by the NASCET method. ${ }^{16}$ Informed consent was obtained for all patients prior to the procedure. Patients were placed on acetylsalicylic acid (ASA) and clopidogrel starting three days before CAS, and were fully heparinized during the procedure. The senior physician in each case was certified for CREST. The most commonly used embolic protection device was the Angioguard (Cordis, Miama, FL) while Protege (ev3 Inc, Plymouth, MN) stents were the most commonly used $(69.3 \%$ and $54.7 \%$, respectively). Patients were admitted to an intensive care unit post-procedure for 12-24 hours, and symptomatic hypertension was treated. Dual anti-platelet drug therapy was continued for a minimum of two months following the procedure, while ASA was continued lifelong. Patients were seen in follow-up between 30 and 90 days following the procedure, which included a detailed history with specific reference to any new or recurrent symptoms, as well as a neurological

\section{Table 1: Baseline patient characteristics}

\begin{tabular}{lc}
\hline \multicolumn{1}{c}{ Characteristic } & $\%$ \\
\hline Age (years) & $69.2 \pm 9.8$ \\
Male Sex & 74.0 \\
Left Side & 40.0 \\
Symptomatic & 89.3 \\
$\quad$ Hemispheric & 70.7 \\
Retinal & 27.2 \\
Both & 2.0 \\
Stenosis $\geq 70 \%$ & 91.6 \\
Stenosis $<70 \%$ & 8.4 \\
\hline
\end{tabular}

examination and carotid Doppler ultrasound. All adverse events were identified and documented by the treating physicians.

Patient baseline characteristics were collected including age, gender, degree of stenosis, presenting symptoms and clinical factors leading to consideration for CAS. Information relating to the treatment included type of anesthesia, pre-medication, use of embolic protection, successful deployment of stent, pre- and post-stent angioplasty, type of stent, and pre- and post-stent stenosis. We analyzed both the 30-day risk of stroke (defined as major ischemic stroke, minor ischemic stroke, and intracerebral haemorrhage), and the composite endpoint of death, stroke and MI. Minor stroke was defined as a modified Rankin scale score of 0-3 at last follow-up while a major stroke was defined as a modified Rankin scale score of 4-6. Patients may have had more than one end point; for example, a fatal myocardial infarction was counted as both death and MI. Other adverse events, including proximal vessel injury during access, and in-stent restenosis, were also recorded. Both the stroke and combined endpoint were then stratified by age $(<70$ versus $\geq 70)$, on the basis of the hazard ratio of the primary endpoints of CAS versus CEA approaching unity at approximately 70 in CREST. ${ }^{13}$ Fisher's exact test (two-tailed) was used to assess proportions and statistical significance fixed at $\mathrm{P} \leq 0.05$.

\section{RESULTS}

A total of 157 patients underwent 165 procedures. Thirty-day follow-up information for six patients $(3<70$ years of age, $3>$ 70 years of age) was unavailable; these patients were excluded from the outcome analysis. Patients were generally symptomatic $(89.1 \%)$ and the presenting symptom was most commonly a hemispheric event $(72.1 \%)$. High- $(70-99 \%)$ and moderate-grade (50-69\%) stenoses were present in $93.9 \%$ and $6.1 \%$ of patients, respectively (Table 1).

The most common reason for referral for CAS was severe cardiopulmonary disease, as defined in SAPPHIRE, ${ }^{9}$ which was the primary indication in $29.3 \%$ of procedures, and present in $43.1 \%$ of the study population. Additionally, 42 patients $(25.4 \%)$ were referred for consideration of CAS as they were felt to be high surgical risk by a vascular surgeon or neurosurgeon but did not meet the specific criteria for high surgical risk set out in the SAPPHIRE trial. Other indications included contralateral occlusion (19.8\%) and previous radical neck surgery or radiation $(5.4 \%)$. When the indications and baseline characteristics were stratified by age, there were no statistically significant differences between the groups. Details of the procedure are summarized in Table 2. Embolic protection was used in $94.3 \%$ of procedures, with successful stent deployment realized in $96.4 \%$ and a reduction of the stenosis on post-procedural ultrasonography to $<50 \%$ in $96.7 \%$.

The composite outcome of death/stroke/MI was $5.0 \%(\mathrm{~N}=8)$ at 24 hours and $8.2 \%(\mathrm{~N}=13)$ at 30 days (Table 3). Alternatively, $6.9 \%(\mathrm{~N}=11)$ of procedures were affected by at least one major complication at 30 days. When stratified by age, the rate of any stroke was $0 \%$ versus $7.4 \% \quad(\mathrm{P}=0.03)$, and the rate of death/stroke/MI $2.6 \%$ versus $13.6 \%(\mathrm{P}=0.02)$, at 30 days in patients $<70$ years of age versus those $\geq 70$, respectively (Table 3 ).

The rate of any stroke was $2.5 \%(\mathrm{~N}=4)$ within 24 hours and $3.8 \%(\mathrm{~N}=6)$ at 30 days (Table 3$)$. Of the four peri-procedural strokes two were minor ipsilateral strokes: one involved an 
Table 2: Procedure-related parameters

\begin{tabular}{lc}
\hline \multicolumn{1}{c}{ Characteristic } & $\%$ (Number) \\
\hline Pre-medication & $98.8(160$ of $162 \dagger)$ \\
Conscious Sedation & $97.0(160$ of 165$)$ \\
Embolic Protection & $92.5(150$ of $159 \dagger)$ \\
Length of Stented Segment $(\mathrm{mm})$ & $32.5 \pm 7.0$ \\
Pre-stent angioplasty & $97.0(160$ of 165$)$ \\
Post-stent angioplasty & $95.8(158$ of 165$)$ \\
Successful Stent Deployment & $96.4(159 \text { of } 165)^{*}$ \\
$<50 \%$ Stenosis on In-Hospital Post- & $96.7(146$ of $151 \dagger)$ \\
Procedure Ultrasound & \\
\hline
\end{tabular}

*One patient was found to have a complete occlusion at the time of stenting and the procedure was aborted. The remainder were unsuccessful. $†$ This information was not documented for all procedures.

increase in facial asymmetry without radiological evidence of new infarction, while the second was confirmed by imaging following increased confusion (the procedure was also complicated by a retroperitoneal hemorrhage; this patient had returned to independent living at one year follow-up). Two of the strokes were reperfusion hemorrhages, of which one was fatal and the other resulted in significant disability $(\mathrm{mRS}=4$ at one year follow-up). Two additional patients suffered minor strokes in the 30 days following the procedure: one presented to the emergency department with a first-time seizure and subsequent neuro-imaging revealed an acute watershed infarct, while the second had a non-disabling reperfusion hemorrhage (mRS score $0-3)$.

Four patients suffered acute MI (2.5\%). One patient suffered an MI within the first 24 hours after the procedure, which was ultimately fatal. The remaining three patients had non-fatal intraprocedural events: one ST segment elevation MI (STEMI) requiring coronary artery bypass surgery seven days later, a nonST elevation MI with mild rise in troponins requiring no further intervention, and a STEMI secondary to dissection involving the root of the aorta in the setting of severe atherosclerosis, requiring the placement of a second carotid stent. There were three deaths in total $(\mathrm{N}=3,1.8 \%)$ : two discussed above, and one as a result of cardiorespiratory failure. Other complications related to the procedure included aortic dissection $(\mathrm{N}=1)$ described above, retroperitoneal hemorrhage $(\mathrm{N}=1)$, groin pseudo-aneurysm $(\mathrm{N}=1$, no treatment required), iliac artery dissection $(\mathrm{N}=1$, no treatment required), and one case of sterile discharge from the puncture site ( $\mathrm{N}=1$, brief course of oral antibiotics).

Although there were few asymptomatic patients there was no statistically significant difference in the outcomes when the procedures were stratified by symptomatology $(\mathrm{P}=0.35)$. Similarly, there was no difference when stratified by presenting symptom type (retinal versus hemispheric, $\mathrm{P}=0.67$ ) or by sex $(\mathrm{P}=0.23)$.

\section{Discussion}

Recent studies have suggested that CAS is a safe alternative to CEA in average risk patients $<70$ years of age. ${ }^{13,15} \mathrm{We}$ describe experience with CAS at a single Canadian academic neuro-vascular centre, reflective of the usage of CAS during the study period, and report the influence of patient age on outcome. The typical patient in this study population was symptomatic, with high-grade stenosis and frequently considered a high surgical risk candidate. Our results compare favourably with similar published studies of patients with symptomatic carotid disease, although direct comparison of our results is best made with studies addressing predominantly symptomatic patients; for example, the SAPPHIRE trial included a majority of asymptomatic patients and therefore is not entirely representative of our patient population. ${ }^{9}$

We sought to evaluate the suggestion that CEA and CAS have similar efficacy and safety in patients $<70$ years. The lead-in phase of the CREST trial suggested that in patients $\geq 80$ years of age CAS had a higher risk of morbidity compared to CEA. ${ }^{16}$ Several retrospective studies also showed higher adverse event rates in the elderly but were not designed for direct comparison with carotid endarterectomy. ${ }^{17,18}$ Subsequently, the final CREST results revealed a statistically significant $(\mathrm{P}=0.02)$ interaction between age and treatment efficacy, suggesting the possibility that below an age of approximately 70 years, and accounting for all primary endpoints, CAS is at least as safe as CEA. ${ }^{13}$ These results must be interpreted cautiously given the known pitfalls of subgroup analysis, however, if nothing else they support further investigation. This age effect was also noted in the interim results of the ICSS, which showed a difference between the complication rates for CAS in those $<70$ compared with those $\geq$ 70 years of age (5.4\% vs $11.2 \%$ at 120 days), although the hazard ratios still favoured CEA and showed no significant difference between age groups ${ }^{14}$ However, when the data were analyzed along with the results of the SPACE and EVA-3S trials, there was no statistically significant difference found between CAS and CEA in those under the age of $70 .{ }^{15}$ In the present study we found that CAS has a significantly lower 30-day rate of stroke and combined death/stroke/MI in those patients $<70$ years of age compared to those $\geq 70$ ( $0 \%$ vs. $7.3 \%, \mathrm{P}=0.03$ and $2.5 \%$ vs. $13.4 \%, \mathrm{P}=0.02$, Table 3 ). These adverse event rates for the younger subpopulation, in comparison to historical adverse event rates for CEA, are particularly favourable and consistent with the results reported in CREST. ${ }^{13}$

It is postulated that the higher complication rate in older patients ( $\geq 70$ years) is in part due to the increased incidence of complex arterial anatomy, complicating vascular access. Lin et al. have found that common and internal carotid artery tortuosity, innominate artery stenosis, and arch calcification are more commonly found in patients greater than 80 years of age. ${ }^{19}$ Similarly, Faggioli et al. found that tortuosity was more common in patients $>80$ years of age and that both proximal carotid tortuosity and age were independent predictors of technical failure..$^{18}$ In this study, four of the five technical failures occurred in the $\geq 70$ year age group. Further supporting the notion that difficult access leads to increased embolic complications, results from a single institution retrospective study of 627 stenting procedures found that $40 \%$ of major strokes occurred during passage of the arch, catheterization of the target vessel and 
Table 3: Overall and age stratified outcomes in carotid angioplasty and stenting

\begin{tabular}{lllll}
\hline $\begin{array}{l}\text { 30-Day } \\
\text { Outcome }\end{array}$ & $\begin{array}{l}\text { All Cases }(\mathrm{N}=159) \\
\%(95 \% \mathrm{CI})\end{array}$ & $\begin{array}{l}\text { Age }<70(\mathrm{~N}=78) \\
\%(95 \% \mathrm{CI})\end{array}$ & $\begin{array}{l}\text { Age } \geq 70(\mathrm{~N}=81) \\
\%(95 \% \mathrm{CI})\end{array}$ & $\begin{array}{l}\text { Fisher's } \\
\text { Exact Test }\end{array}$ \\
\hline $\begin{array}{l}\text { Death } \\
\text { Stroke }\end{array}$ & $1.9(0.4-5.4)$ & $0(0-3.8)$ & $3.7(0.8-10.4)$ & \\
$\quad$ Any & $3.8(1.4-8.0)$ & $0(0-3.8)$ & $7.4(2.8-15.4)$ & $\mathrm{P}=0.03$ \\
$\quad \begin{array}{l}\text { Minor Ischemic } \\
\quad \text { Major Ischemic }\end{array}$ & $1.9(0.4-5.4)$ & $0(0-3.8)$ & $3.7(0.8-10.4)$ & $0(0-3.6)$ \\
$\quad$ Reperfusion Hemorrhage & $0(0-1.9)$ & $0(0-3.8)$ & $3.7(0.8-10.4)$ & \\
MI & $1.9(0.4-5.4)$ & $2.6(0.3-9.0)$ & $2.5(0.3-8.6)$ & $13.6(7.0-23.0)$ \\
Death/Stroke/MI & $2.5(0.7-6.3)$ & $2.6(0.3-9.0)$ & & $\mathrm{P}=0.02$ \\
\hline
\end{tabular}

$\mathrm{MI}=$ myocardial infarction

insertion of a guidewire or sheath. ${ }^{20}$ Embolic events occurring proximal to the target vessel are not uncommon; a study of CAS in high-surgical risk patients found that $40 \%$ of patients had new diffusion positive lesions on MRI and in $62 \%$ of these there were lesions identified outside of the territory of the treated vessel. ${ }^{21}$ Kim et al have shown that diffusion-positive lesions are seen significantly more frequently in patients $\geq 65$ years of age and, are more prone to multiple lesions and lesions outside the territory of the treated carotid artery. ${ }^{22}$ All of the ischemic strokes in our study population occurred in the older age group, and two out of three occurred within the first 24 hours, demonstrating consistency with other published results and implicating the procedure directly.

A frequently voiced concern with CAS in younger patients is the longer anticipated lifespan and the possibility of in-stent restenosis. A recent meta-analysis by Yavin et al of 12 randomized controlled trials comparing CAS and CEA, involving a total of 6,973 patients, found a trend toward increased restenosis in CAS, but the difference was not statistically significant. ${ }^{23}$ We have had only one symptomatic restenosis at our institution during the study period, which is in keeping with the extremely low rate of symptomatic restenoses in the literature. ${ }^{12}$ Whether long-term surveillance of these patients is needed remains unanswered at the present time. The same meta-analysis also found, not surprisingly, an increased rate of stroke but decreased rate of MI with CAS compared with CEA. This suggests that particularly in young patients with cardiac disease, for whom treatment is indicated, CAS might be the treatment modality of choice.

Our series has several limitations. The study is retrospective in nature and thus patients were monitored, and the adverse events recorded, by the treating physicians at the time of their respective procedures; however, since this review was not preplanned, significant bias would only have been introduced if the treating physicians had a preconceived notion about the risk of CAS as a function of age, which is unlikely. Our study does not have a surgery arm to which we can directly compare CAS, although there are sufficient trials in the published literature that the average complication rate for CEA is well documented. Routine troponins were not drawn for all patients and we are aware that a significant proportion of MI's, particularly in patients undergoing surgery with a general anesthetic, may be missed. However, only $3 \%$ of the patients received a general anesthetic. Also, since routine MRI imaging was not done at 30 days, minor strokes could have been missed in some patients, possibly more in the younger patient group, particularly if they are better able to tolerate this insult. However, it is questionable whether these events would be of any functional significance for the patient, if they occurred. In fact, all of the ischemic strokes that were captured in our study were minor events.

\section{Conclusion}

In the post-CREST era, both CEA and CAS are reasonable options in the management of carotid stenosis. An increasing body of literature exists suggesting that patients $<70$ years of age may be safely managed with CAS. ${ }^{13,15}$ These are important findings given that, up until recently, CAS was frequently reserved only for patients who were deemed high-risk for CEA. Results from this single centre retrospective review, in conjunction with those from CREST and the recent Carotid Stenting Trialists' Collaboration meta-analysis, provide evidence for CAS as an alternative for patients under 70 years of age, and reinforces the need for careful patient selection when undertaking CAS in those $\geq 70$ years of age.

\section{ACKNOWLEDGEMENTS}

The authors would like to acknowledge the Bitove Foundation for establishing the Bitove Family Fellowship in Neuroendovascular Therapeutics at St. Michael's Hospital. 


\section{REFERENCES}

1. CANSIM Database [Internet] Ottawa: Statistics Canada; 20002008, Deaths, by cause, Chapter IX: Diseases of the circulatory system (I00 to I99), age group and sex, Canada, annual (number) [cited 2010 Dec 27]. Available from: http://cansim2.statcan. gc.ca/cgi-win/cnsmcgi.exe?Lang=E\&CNSM-Fi=CII/CII_1eng.htm Unique ID: 102-0529

2. National Heart, Lung, and Blood Institute. Morbidity and Mortality: 2009 Chart Book on Cardiovascular, Lung and Blood Diseases [Internet]. Bethesda: National Institutes of Health; 2009 [cited 2010 December 27]. Available from: http://www.nhlbi.nih.gov/ resources/docs/2009_ChartBook_508.pdf

3. Petty GW, Brown RD Jr, Whisnant JP, Sicks JD, O'Fallon WM, Wiebers DO. Ischemic stroke subtypes: a population based study of incidence and risk factors. Stroke. 1999;30:2513-16.

4. North American Symptomatic Carotid Endarterectomy Trial Collaborators. Beneficial effect of carotid endarterectomy in symptomatic patients with high grade carotid stenosis. N Engl J Med. 1991;325:445-53.

5. European Carotid Surgery Trialists' Collaborative Group. MRC European Carotid Surgery Trial: interim results for symptomatic patients with severe (70-99\%) or with mild (0-29\%) carotid stenosis. Lancet. 1991;337:1235-43.

6. The European Carotid Surgery Trialists' Collaborative Group. Risk of stroke in the distribution of an asymptomatic carotid artery. Lancet. 1995;345:209-12.

7. Executive Committee for the Asymptomatic Carotid Atherosclerosis Study. Endarterectomy for asymptomatic carotid artery stenosis. JAMA. 1995;273:1421-8.

8. MRC Asymptomatic Carotid Surgery Trial (ACST) Collaborative Group. Prevention of disabling and fatal strokes by successful carotid endarterectomy in patients without recent neurological symptoms: randomised controlled trial. Lancet. 2004;363: 1491-502.

9. Stenting and Angioplasty with Protection in Patients at High Risk for Endarterectomy Investigators. Protected carotid-artery stenting versus endarterectomy in high-risk patients. N Engl J Med. 2004;351:1493-501.

10. EVA-3S investigators. Endarterectomy Versus Angioplasty in Patients with Symptomatic Severe Carotid Stenosis (EVA-3S) trial: results up to 4 years from a randomised, multicentre trial. Lancet Neurol. 2008;7:885-92.

11. Eckstein HH, Ringleb P, Allenberg JR, et al. Results of the StentProtected Angioplasty versus Carotid Endarterectomy (SPACE) study to treat symptomatic stenoses at 2 years: a multinational, prospective, randomised trial. Lancet Neurol. 2008;7(10):893902.
12. Bonati LH, Ederle J, McCabe DJ, et al. Long-term risk of carotid restenosis in patients randomly assigned to endovascular treatment or endarterectomy in the Carotid and Vertebral Artery Transluminal Angioplasty Study (CAVATAS): long-term followup of a randomised trial. Lancet Neurol. 2009;8(10):908-17.

13. CREST Investigators. Stenting versus endarterectomy for treatment of carotid-artery stenosis. N Engl J Med. 2010;363:11-23.

14. International Carotid Stenting Study investigators. Carotid artery stenting compared with endarterectomy in patients with symptomatic carotid stenosis (International Carotid Stenting Study): an interim analysis of a randomised controlled trial. Lancet. 2010;375:985-97.

15. Carotid Stenting Trialists' Collaboration. Short-term outcome after stenting versus endarterectomy for symptomatic carotid stenosis: a preplanned meta-analysis of individual patient data. Lancet. 2010;376:1062-73.

16. Fox AJ. How to measure carotid stenosis. Radiology. 1993;186: 316-18.

17. CREST Investigators. Carotid artery stenting is associated with increased complications in octogenarians: 30-day stroke and death rates in the CREST lead-in phase. J Vasc Surg. 2004;40: 1106-11.

18. Faggioli G, Ferri M, Gargiulo M, et al. Measurement and impact of proximal and distal tortuosity in carotid stenting procedures. J Vasc Surg. 2007;46:1119-24.

19. Lin SC, Trocciola SM, Rhee J, et al. Analysis of anatomic factors and age in patients undergoing carotid angioplasty and stenting. Ann Vasc Surg. 2005; 19:798-804.

20. Verzini F, Cao P, De Rango P, et al. Appropriateness of learning curve for carotid artery stenting: an analysis of periprocedural complications. J Vasc Surg. 2006;44:1205-11.

21. Hammer FD, Lacroix V, Duprez T, et al. Cerebral microembolization after protected carotid artery stenting in surgical high risk patients: results of a 2-year prospective study. J Vasc Surg. 2005;42:847-53.

22. Kim HJ, Lee HJ, Yang JH, et al. The influence of carotid artery catheterization technique on the incidence of thromboembolism during carotid artery stenting. Am J Neuroradiol. 2010;31: 1732-6.

23. Yavin D, Roberts DJ, Tso M, Sutherland GR, Eliasziw M, Wong JH. Carotid endarterectomy versus stenting: a meta-analysis of randomized trials. Can J Neurol Sci. 2011;38(2):230-5. 